Status and Threats Analysis for the Florida Manatee (Trichechus manatus latirostris), 2012

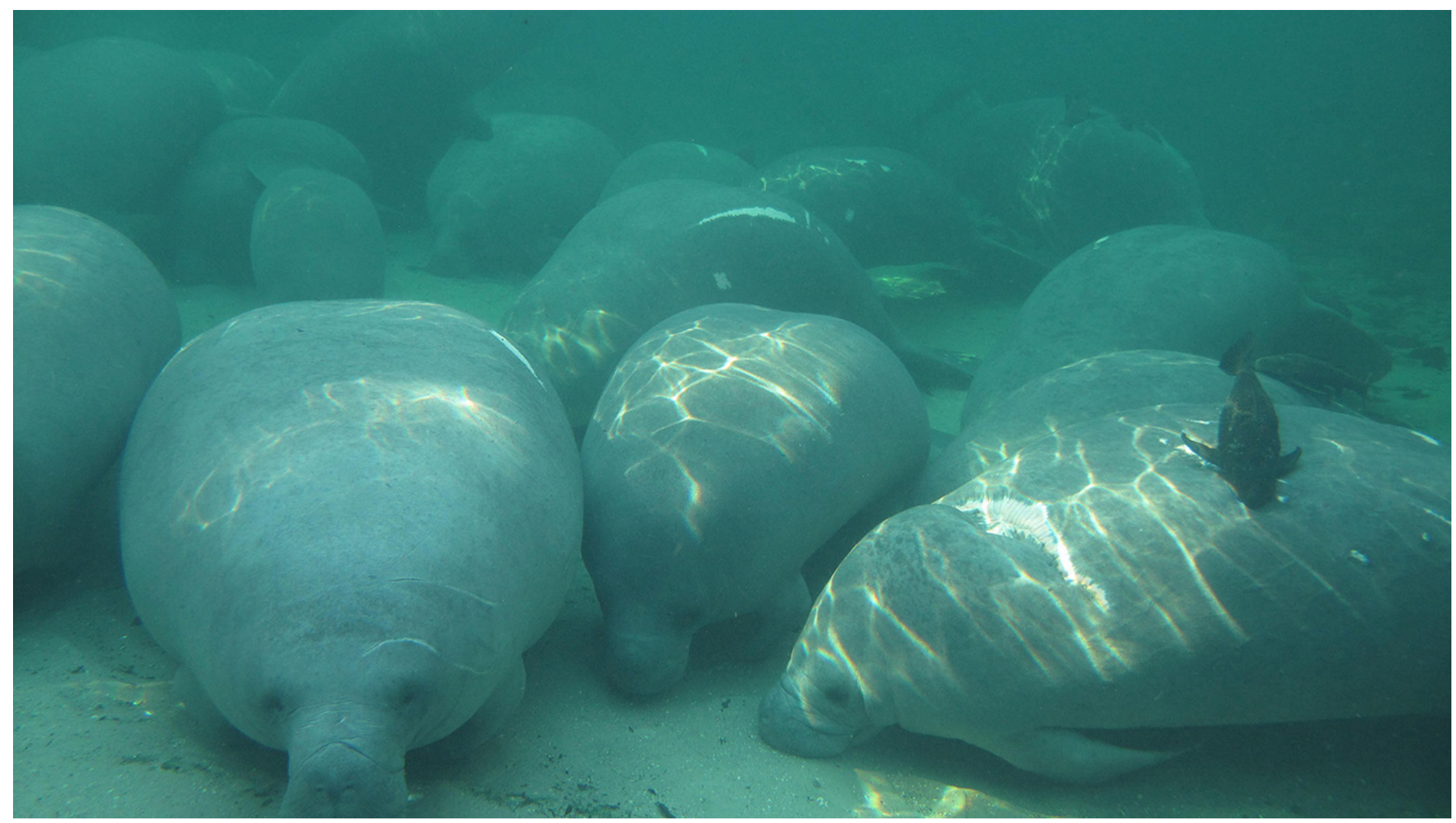

Open-File Report 2015-1083 
Front cover photograph: Florida manatees overwintering in the warm spring run at Blue Spring State Park, 15 January 2010. Note the scars on several of the manatees, used for individual identification. Photo credit, Amy Teague, U.S. Geological Survey. 


\section{Status and Threats Analysis for the Florida Manatee (Trichechus manatus latirostris), 2012}

By Michael C. Runge, Catherine A. Langtimm, Julien Martin, and Christopher J. Fonnesbeck

Open-File Report 2015-1083

U.S. Department of the Interior

U.S. Geological Survey 


\section{U.S. Department of the Interior \\ SALLY JEWELL, Secretary}

\section{U.S. Geological Survey \\ Suzette M. Kimball, Acting Director}

U.S. Geological Survey, Reston, Virginia: 2015

For more information on the USGS—-the Federal source for science about the Earth, its natural and living resources, natural hazards, and the environment-visit http://www.usgs.gov/ or call 1-888-ASK-USGS (1-888-275-8747).

For an overview of USGS information products, including maps, imagery, and publications, visit http://www.usgs.gov/pubprod/.

Any use of trade, firm, or product names is for descriptive purposes only and does not imply endorsement by the U.S. Government.

Although this information product, for the most part, is in the public domain, it also may contain copyrighted materials as noted in the text. Permission to reproduce copyrighted items must be secured from the copyright owner.

Suggested citation:

Runge, M.C., Langtimm, C.A., Martin, Julien, and Fonnesbeck, C.J., 2015, Status and threats analysis for the Florida manatee (Trichechus manatus latirostris), 2012: U.S. Geological Survey Open-File Report 2015-1083, 23 p., at http://dx.doi.org/10.3133/ofr20151083.

ISSN 2331-1258 (online) 


\section{Contents}

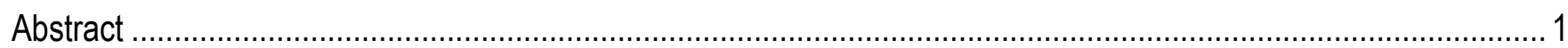

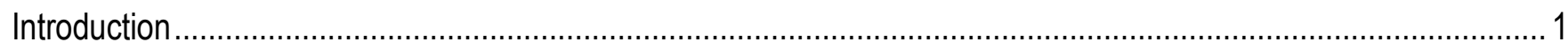

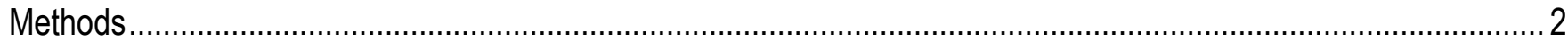

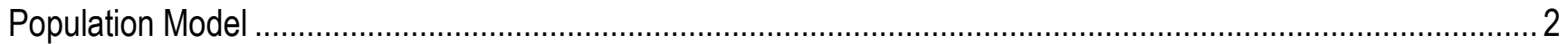

Warm-Water Carrying Capacity ........................................................................................................... 3

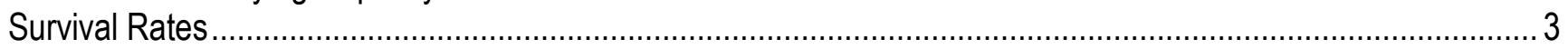

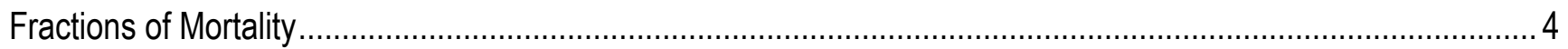

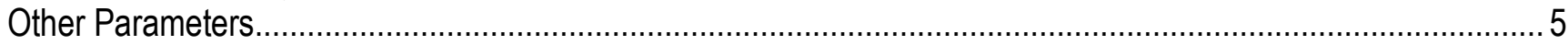

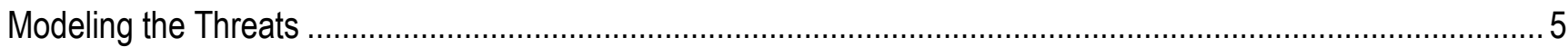

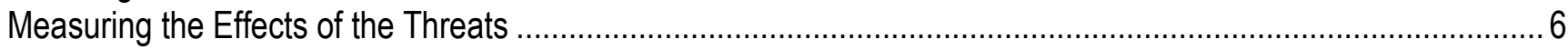

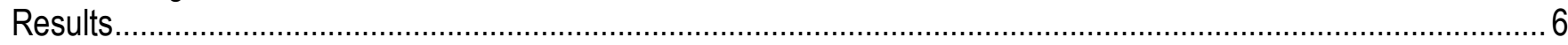

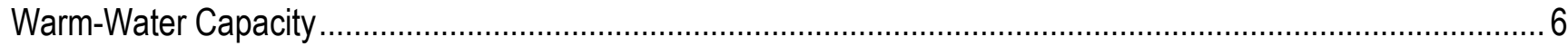

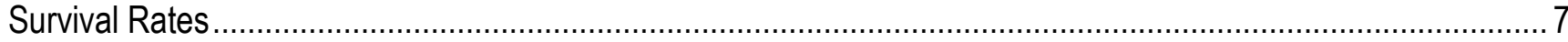

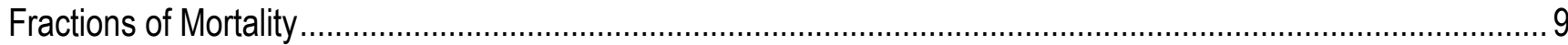

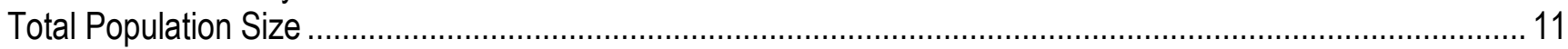

Regional Analysis of Quasi-Extinction................................................................................................ 13

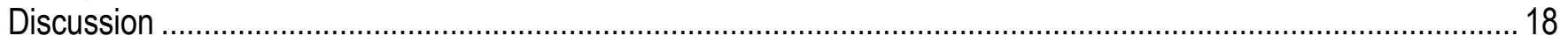

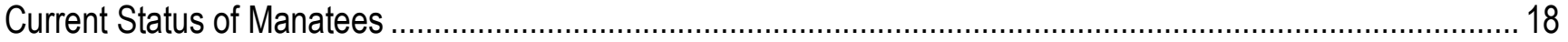

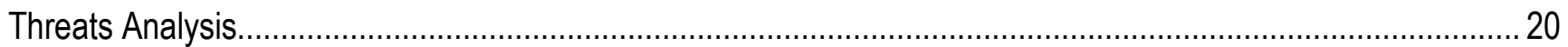

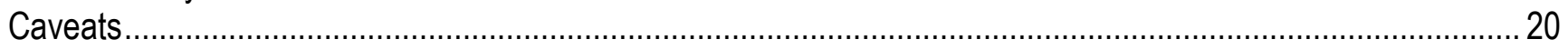

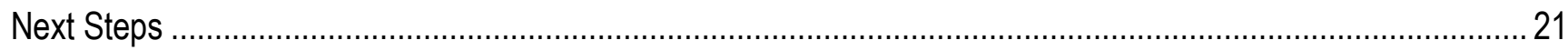

Acknowledgments

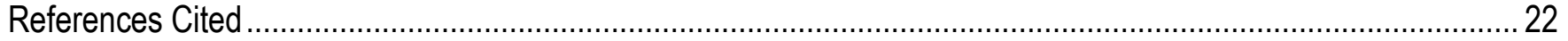

\section{Figures}

1. Estimated manatee warm-water capacity over time, associated with $A$, high-quality, $B$, medium-quality, and $C$, total warm-water sites in Florida, 2010-2110.

2. Contour plot of the asymptotic population growth rate $(\lambda)$ as a function of adult survival rate and breeding rate

3. Histograms of fraction of adult mortality resulting from watercraft, based on data from 2001 to 2009 for the $A$, Southwest and $B$, Atlantic regions of Florida.

4. Projected Florida manatee population size under the status quo scenario, 2010-2110 ........................... 12

5. Projected adult population size in four regions of Florida, 2010-2110 ( 0 to 100 years from now), under the status quo scenario.

6. Probability of the adult (effective) population falling below a threshold within 50,100 , or 150 years, as a function of the threshold, for the status quo scenario, on $A$, the Gulf coast, $B$, the East coast, or $C$, either coast of Florida...

7. Probability of the adult (effective) population falling below a threshold within 150 years, as a function of the threshold, for the status quo and six threat scenarios, on $A$, the Gulf coast, or $B$, the East coast of Florida.

8. Probability of the adult (effective) population falling below a threshold on either the Gulf or the East coast of Florida within 150 years, as a function of the threshold, for the status quo and six threat scenarios 


\section{Tables}

1. Florida manatee adult survival rates for four regions in Florida, 1983-2007. .......................................... 8

2. Fractions of mortality due to various causes based on Bayesian analysis of the carcass salvage data, $200-09$.

3. Probability of the adult population falling below 100,250 , or 500 animals on either the Gulf coast or the East coast of Florida in 50 to 150 years. 


\section{Conversion Factors}

Inch/Pound to SI

\begin{tabular}{lcl}
\hline \multicolumn{1}{c}{ Multiply } & By & \multicolumn{1}{c}{ To obtain } \\
\hline inch (in.) & \multicolumn{1}{c}{ Length } & \\
inch (in.) & 2.54 & centimeter (cm) \\
foot (ft) & 25.4 & millimeter (mm) \\
mile (mi) & 0.3048 & meter (m) \\
mile, nautical (nmi) & 1.609 & kilometer (km) \\
yard (yd) & 1.852 & kilometer (km) \\
\hline
\end{tabular}

Temperature in degrees Celsius $\left({ }^{\circ} \mathrm{C}\right)$ may be converted to degrees Fahrenheit $\left({ }^{\circ} \mathrm{F}\right)$ as follows:

${ }^{\circ} \mathrm{F}=\left(1.8 x^{\circ} \mathrm{C}\right)+32$

Temperature in degrees Fahrenheit $\left({ }^{\circ} \mathrm{F}\right)$ may be converted to degrees Celsius $\left({ }^{\circ} \mathrm{C}\right)$ as follows:

${ }^{\circ} \mathrm{C}=\left({ }^{\circ} \mathrm{F}-32\right) / 1.8$

\section{Abbreviations Used}

$\begin{array}{ll}\text { AC } & \text { Atlantic Coast region } \\ \text { Barker/RD } & \text { Barker closed-population robust design model } \\ \text { CBM } & \text { Core Biological Model } \\ \text { DOI } & \text { U.S. Department of the Interior } \\ \text { ESA } & \text { Endangered Species Act of 1973 } \\ \text { FWRI } & \text { Florida Fish and Wildlife Research Institute } \\ \text { FWS } & \text { U.S. Fish \& Wildlife Service, Department of the Interior } \\ \text { MIPS } & \text { Manatee Individual Photo-identification System } \\ \text { Mote } & \text { Mote Marine Laboratory } \\ \text { NW } & \text { Northwest region } \\ \text { SW } & \text { Southwest region } \\ \text { USGS } & \text { U.S. Geological Survey, Department of the Interior } \\ \text { USJ } & \text { Upper St. Johns region } \\ \text { WCS } & \text { Water-control structure }\end{array}$




\title{
Status and Threats Analysis for the Florida Manatee (Trichechus manatus latirostris), 2012
}

\author{
By Michael C. Runge, ${ }^{1}$ Catherine A. Langtimm, ${ }^{2}$ Julien Martin, ${ }^{2}$ and Christopher J. Fonnesbeck ${ }^{3}$
}

\begin{abstract}
The endangered West Indian manatee (Trichechus manatus), especially the Florida subspecies (T. m. latirostris), has been the focus of conservation efforts and extensive research since its listing under the Endangered Species Act. On the basis of the best information available as of December 2012, the threats facing the Florida manatee were determined to be less severe than previously thought, either because the conservation efforts have been successful, or because our knowledge of the demographic effects of those threats is increased, or both. Using the manatee Core Biological Model, we estimated the probability of the Florida manatee population on either the Atlantic or Gulf coast falling below 500 adults in the next 150 years to be 0.92 percent. The primary threats remain watercraft-related mortality and long-term loss of warm-water habitat. Since 2009, however, there have been a number of unusual events that have not yet been incorporated into this analysis, including several severely cold winters, a severe red-tide die off, and substantial loss of seagrass habitat in Brevard County, Fla. Further, the version of the Core Biological Model used in 2012 makes a number of assumptions that are under investigation. A revision of the Core Biological Model and an update of this quantitative threats analysis are underway as of 2015 .
\end{abstract}

\section{Introduction}

In 2007, the U.S. Fish and Wildlife Service (FWS) published a 5-year status review of the West Indian manatee (Trichechus manatus Linnaeus; FWS, 2007), incorporating a U.S. Geological Survey(USGS) led quantitative threats analysis for the Florida manatee (Trichechus manatus latirostris; Runge and others, 2007b). In preparation for a new 5-year status review, this threats analysis is being updated. This report contains preliminary results from such a threats analysis; information is current as of December 2012. On March 1, 2013, the stipulations of the Budget Control Act of 2011 (Publ. L. 11225 ) led to automatic spending cuts (sequestration) across many Federal agencies, including the Department of the Interior. As a result of sequestration, work on the 5-year status review and work on the quantitative threats analysis ceased. Work is beginning in 2015 to update the threats analysis with the most current information, but this report is being provided as an interim source of information.

Like the 2007 threats analysis, this study uses a quantitative approach grounded in the assumption that an appropriate measure of status under the Endangered Species Act (ESA; 16 U.S.C. § 1531 et seq.) is based on the risk of extinction, as quantified by the probability of quasi-extinction. This study is related to the qualitative threats analyses that are more common under the ESA but provides an

${ }^{1}$ U.S. Geological Survey, Patuxent Wildlife Research Center, Laurel, Md.

${ }^{2}$ U.S. Geological Survey, Southeast Ecological Science Center, Gainesville, Fla.

${ }^{3}$ Vanderbilt University School of Medicine, Department of Biostatistics, Nashville, Tenn. 
additional level of rigor, objectivity, and integration. In this approach, our philosophy is that analysis of the five threat factors described in Section 4(a)(1) of the ESA (habitat loss, overutilization, disease or predation, inadequacy of existing regulatory mechanisms, and other natural or manmade factors) can be undertaken within an overarching quantitative framework. The use of the probability of quasi-extinction as a metric can integrate the threats identified by the five factors, quantify their relative effects, and provide an understanding of the trade-offs among them.

Florida manatee populations have experienced a number of unusual events since the last 5-year status review (FWS, 2007) that are not yet reflected in the analysis in this report: severe cold in the winters of 2009-10 and 2010-11, extensive loss of seagrass habitat in Indian River Lagoon in Brevard County, Fla., in 2011 and 2012, a severe red tide in the Southwest region in 2013; and an unusual mortality event of unknown cause in Brevard County in 2013. The potential effects of these particular events is being explored in 2015 .

This report presents survival rates for Florida manatees, fractions of mortality resulting from various causes, and the probability of the adult population falling below 100, 250, or 500 manatees in four regions in Florida using data available as of 2012. The relative strength of various threats to the persistence of Florida manatees are shown in figures and tables.

\section{Methods}

The basis of this threats analysis is a comparative population viability analysis. This involves forecasting the Florida manatee population under scenarios that differ in the presence of various threats, while accounting for process variation (environmental, demographic, and catastrophic stochasticity), as well as parametric and structural uncertainty. The description of the methods in the 2007 threats analysis (Runge and others, 2007b) largely holds, but we have been able to update a number of aspects. The structure of the core model has been updated, new estimates of warm-water capacity have been produced, and new estimates are available for most of the parameters in the model, including survival rates and fractions of mortality.

\section{Population Model}

The Manatee Core Biological Model (CBM) (Runge and others, 2007a) was used as the modeling framework for this analysis. This model is a stage-based projection model for Florida manatees, incorporating environmental and demographic stochasticity, catastrophes, density dependence, and long-term change in carrying capacity. The model tracks manatees in the four geographic regions of Florida (Atlantic, Upper St. Johns, Northwest, and Southwest) separately and does not account for movement between them. Importantly, the CBM explicitly incorporates uncertainty about the parameters in the model.

The structure of the CBM (version 5.03) was updated in several ways. First and most importantly, we developed a more nuanced method of incorporating density dependence resulting from winter habitat limitation. A panel of experts (see the section "Warm-Water Capacity") had recommended distinguishing high- and medium-quality warm-water sites, estimating capacity separately for those classes of sites, and applying differential mortality in those classes of sites during severe, cold, and mild winters. These dynamics, along with behavioral rules for the manner in which manatees choose among these sites, have been incorporated. There are several ways that manatees may choose sites; the CBM allows for the incorporation of structural uncertainty about this behavior by including several different mechanisms. Under the "ideal despotic" distribution hypothesis, manatees preferentially choose high-quality sites, then spill into medium-quality sites once the high-quality sites 
are filled. To reflect the attractiveness of industrial sites, the results included in this report use the "ecological trap" distribution hypothesis in which manatees preferentially choose medium-quality industrial sites over high-quality natural sites and spill into medium-quality natural sites only if the other two classes are filled. Second, recent survival analyses (see the section "Survival Rates") have identified an important red-tide effect in certain years in the Southwest region. This information was used to incorporate a better representation of severe red-tide effects than had been previously modeled (as a "Type 2 catastrophe", Runge and others, 2007a). Other changes to the CBM largely govern how parameters were estimated.

We examined five major threats identified in the Manatee Recovery Plan: watercraft-related mortality, loss of warm-water habitat, red tide, mortality in water-control structures (gates and locks), and mortality resulting from interaction with marine debris (for example, fishing lines, trap lines). The details of how we modeled these threats are presented in subsequent sections.

\section{Warm-Water Carrying Capacity}

Between November 2011 and May 2012, an expert elicitation process was undertaken to estimate the carrying capacity for manatees in the State of Florida, currently and through the next century. An expert panel was convened with participants from Federal agencies, state agencies, nongovernmental organizations, and private industry. The combined judgement of the expert panel was that the availability of winter refugia acts as a limiting factor for the population size of Florida manatees. The panel defined carrying capacity as the number of manatees that could survive winters of varying severity, taking into account the spatial extent of thermal refuges; the availability of food resources in proximity to those refuges; and the behavior of manatees, including their tolerance for human disturbance. The panel had access to a recent study of warm-water site characteristics (Provancha and others, 2012) but also took into account other considerations. The panel distinguished high-quality capacity (capacity associated with natural warm-water sites that provide water of at least 22 degrees Celsius $\left[{ }^{\circ} \mathrm{C}\right]$, even in the most severe winters) and medium-quality capacity (capacity associated with natural or industrial warm-water sites that provide water of at least $18{ }^{\circ} \mathrm{C}$ in severe winters and $20{ }^{\circ} \mathrm{C}$ in most cold winters). The panel forecast losses in warm-water habitat over the next century, primarily driven by reduction in spring flow and retirement of power generation plants that produce warm effluent.

\section{Survival Rates}

Since the 2007 FWS 5-year status review, the database managers at USGS Sirenia Project, Florida Fish and Wildlife Research Institute (FWRI), and Mote Marine Laboratory (Mote) completed a major upgrade of the Interagency Manatee Individual Photo-Identification System (MIPS), which now includes the use of digital images and common protocols for collecting and processing data, storing data in a common database, and error checking. Additional years of monitoring data, both live sightings and dead recovery, were added to the database. By the end of 2012, however, data processing had not yet been completed for the extreme cold winters of 2009-2010 and 2010-2011, which killed a large number of manatees as documented by carcass recovery and necropsy data (Barlas and others, 2011).

Individual manataees were included in the analysis according to the selection rules described in previous publications (Langtimm and others, 1998; Langtimm and others, 2004; Runge and others, 2007a). Annual survival estimates were based on the entire period of record, for which the sampling periods were winter 1982-83 through 2008-09 for the Northwest and Atlantic regions, winter 1985-86 through 2008-09 for the Upper St. Johns region, and winter 1995-96 through 2008-09 for the Southwest region. 
A new mark-recapture statistical model was applied to the data that accounts for bias in survival estimates at the end of the time series identified in previous work (Langtimm and others, 2004;

Langtimm, 2009). The Barker closed-population robust design (Barker/RD) model (Kendall and others, 2013) jointly analyzes three types of data-live sightings of MIPS individuals at the major aggregation sites during the winter season, additional live sightings of those individuals at other locations (anywhere in the southeastern United States) and at other times, and matches to recovered dead carcasses. A simulation study based on analyses of data generated under known parameters of survival, detection, and dead recovery rates demonstrated reduced bias and increased precision using this modeling approach (Peñaloza and others, 2014). The model was run in the program MARK (White and Burnham, 1999).

We determined mean annual survival rate for the period of record for each region, but because of possible remaining bias as documented in the simulation study (Peñaloza and others, 2014), we dropped the survival estimate for 2008 for all regions. We calculated temporal variance according to the method of Burnham and others (1987). In the Southwest region, we included a covariate for severe red-tide years $(1996,2003,2005,2006)$ and estimated the additional mortality rate for those years.

\section{Fractions of Mortality}

In order to model the effects of several of the threats, an estimate of the fractions of mortality resulting from each of six causes (watercraft, water-control structures, interaction with marine debris, cold, red tide, and other) was needed. We used data from the Florida Fish and Wildlife Conservation Commission's manatee carcass recovery program, 2001-09. Causes of mortality were tabulated for adults (body length $>265$ centimeters [cm]), subadults $(236-265 \mathrm{~cm})$ and calves $(151-235 \mathrm{~cm})$ in each region. Carcasses from perinatal mortalities were not included in the analysis. In the fractions-ofmortality analysis, adults and subadults were combined into a single "adult" category (adults and subadults are treated separately in the survival analyses and the population model itself). Note that this size classification differs from that used in the previous analysis (Runge and others, 2007b). The cause of death cannot be determined for a substantial proportion (approximately one-third) of the recovered carcasses, and the fraction of mortality resulting from each cause may be different in the unknown cases than in the known cases. This creates considerable uncertainty in the estimate of the overall fractions of mortality; accounting for this uncertainty was a primary purpose of the analysis of these data. To estimate these underlying fractions of mortality and their uncertainty, we built a Bayesian hierarchical model that captured the sampling processes for both the known and unknown carcasses. Cause of death proportions (for known and unknown carcasses together) were specified as the parameters of a multinomial distribution. We assumed the known carcasses were correctly classified. We modeled the causes of death for the unknown carcasses as a multinomial distribution with fractions of mortality that could differ from the fractions for the known carcasses. For the Southwest region, an effect owing to severe red-tide years $(2003,2005,2006)$ was included. A weak prior distribution (Dirichlet $[1,1,1,1,1,1])$ was placed on the fractions of mortality in the unknown carcasses; this distribution gives no prior preference to any cause of death in the carcasses of unknown cause. Sensitivity of the results to the prior distribution was investigated, and only a minor effect was found. No compelling case could be made for an alternative prior distribution. Parameters were estimated by Markov Chain Monte Carlo using Dr. C.J. Fonnesbeck's software, PyMC. Chains of the length 1,000,000 were generated, a 900,000 iteration burn-in sample was removed, and the remaining sample thinned by a factor of 10 to produce a posterior sample of 10,000 . The posterior distributions of the fractions of mortality in the population were used in the CBM to capture the uncertainty in these parameters. 


\section{Other Parameters}

Nearly all of the other parameters in the CBM were reviewed and updated following the same methods used in Runge and others (2007a). The details are not included here, except to note that the 2011 synoptic survey results were used as the starting population sizes in each region.

\section{Modeling the Threats}

The methods for modeling the threats are unchanged from Runge and others (2007b) but are reiterated here for clarity. We removed the five threats one at a time and compared the results of the model to the status quo (the baseline parameters in the CBM project the population in the continued presence of all identified threats). It is important to note that these scenarios were "all or nothing"; either a particular threat was there at its current level (and remained at that level indefinitely) or it was removed completely.

For three of the threats (mortality owing to watercraft, water-control structures, and entanglement in marine debris), we "removed" the threat by reducing regional mortality of adults and calves by the fractions estimated with the Bayesian methods described above. This assumes that the causes of mortality are additive, not compensatory. For instance, in a particular replicate, if the status quo scenario had an adult survival rate of 0.94 , and the fraction of adult mortality owing to watercraft was 40 percent, then the "no watercraft mortality" scenario used an adult survival rate of 0.964 (this is a $40 \%$ interpolation between 0.94 and 1.0). To account for uncertainty, each replicate has a different base survival rate and fraction of mortality, based on the sampling distributions for each. The fractions of adult mortality were applied to the survival rates for subadults (age 3+) and adults; the fractions of calf mortality were applied to the survival rates for first- and second-year calves. Note that the fractions of mortality owing to cold and background red tide (different from severe red tide) were treated as part of the baseline mortality and were not removed in any of the scenarios.

For the threat resulting from loss of warm-water habitat, we removed the threat in the model by maintaining winter warm-water capacity at current levels for the indefinite future, rather than having that capacity drop at the currently anticipated rates. For manatees that rely primarily on first-order springs (Upper St. Johns and Northwest regions), this could happen either by preservation of existing spring flow and protection (through management of minimum flow levels, such as proposed for Blue Spring [Rouhani and others, 2007]) or by mitigation that exactly matches the anticipated loss (for example, through increasing access to and protection of other springs). For manatees that rely primarily on industrial warm-water effluents (Atlantic and Southwest regions), this could happen by maintaining those industrial effluents at their existing levels, through restoration of natural habitats in those areas, or by replacing lost warm-water capacity using alternative technologies (for example, solar-heated refuges). Note that in the scenario that removed this threat, cold-related mortality owing to loss of warm-water capacity was reduced, but background, density-independent cold-related mortality (as captured in the fractions-of-mortality analysis) remained.

For red tide, we removed the threat from the model by setting the probability of occurrence of a severe red-tide event to zero. Background levels of red-tide mortality occur every year and are already incorporated into the estimates of survival. In the CBM, catastrophic red-tide mortality represents the periods of severe mortality events. An expert panel projected that these events will occur with 45percent frequency $(80 \%$ uncertainty range, $19-74 \%)$ in the Southwest region, 8 percent $(80 \%$ uncertainty range, $0-15 \%)$ in the Northwest region, and 15 percent ( $80 \%$ uncertainty range, $6-25 \%)$ in the Atlantic region. In the survival analysis for the Southwest region, a severe red-tide year reduced survival by 2.17 percent (standard error, $0.84 \%$ ). The expert panel estimated that this effect would be only 35 percent as large (14-55\%) in the Northwest region and 38\% as large (18-58\%) in the Atlantic 
region. To project the population in the absence of this threat, the probability of severe red-tide mortality was set to zero. But note that background levels of red-tide remain, particularly in the Southwest region.

\section{Measuring the Effects of the Threats}

We examined the population size over time under the six scenarios considered (status quo plus removal of each of the five threats, one at a time). To provide context, trends in the total population size were included, but the focus was on examining quasi-extinction over different time frames and for different levels of effective population size. We assumed that a relevant measure of status, for classification under the ESA and perhaps for other purposes, can be expressed as the probability of quasi-extinction over the ensuing $y$ years, where quasi-extinction is defined as an effective population size of fewer than $z$ on either the East coast or the Gulf coast. Note that $y$ and the probabilities of quasiextinction that designate a change in status are policy parameters that have not yet been determined for manatees; given that, the results over a reasonable range of values are presented in the "Results" section. The threshold effective population for quasi-extinction, $z$, is governed more by biology than policy, but a level has not yet been agreed upon, so we present a range of values. The East coast comprises the Upper St. Johns and Atlantic regions, and the Gulf coast comprises the Northwest and Southwest regions. In the analysis, we equated the effective population size with the adult population size, based on the open mating system of manatees. (In the population model, adults include females 4.5 years and older that have previously bred and males 4.5 years and older.) After this analysis was completed in 2012, a new study estimated the ratio of effective population size to adult population size to be about 0.5 for Florida manatees (Tucker and others, 2012). This new understanding will be incorporated into future updates of the CBM and should be taken into account when interpreting the results herein (for example, if the desire is to evaluate the probability of quasi-extinction for an effective population size of 250 , the results associated with an adult population size of 500 need to be examined).

These probabilities of quasi-extinction, then, serve as a measure of status of the population and are compared across scenarios with different threats removed. This comparison provides a measure of the relative effect of each threat on the manatee population.

\section{Results}

\section{Warm-Water Capacity}

Statewide, the median estimate of current capacity at all high-quality sites was 5,309 individuals (80\% credible interval [CI], 2,425-12,464 individuals; fig. $1 A)$, and the median estimate of current capacity at medium-quality sites was 10,122 individuals $(80 \% \mathrm{CI}, 6,528-17,345$ individuals; fig. $1 B)$. Over the next century (2010-2110), a significant portion of this capacity is expected to be lost through retirement of industrial facilities and reduction in spring flow. Statewide, the median estimate of longterm high-quality capacity was 4,251 individuals (80\% CI, 1,909-9,873 individuals; fig. $1 A)$ and medium-quality capacity was 2,353 $(80 \% \mathrm{CI}, 1,072-6,326$ individuals; fig. $1 B)$. That is, the average long-term loss of capacity is expected to be 18.6 percent $(10.8-30.3 \%)$ at high-quality sites, and 75.5 percent $(49.8-88.8 \%)$ at medium-quality sites. 

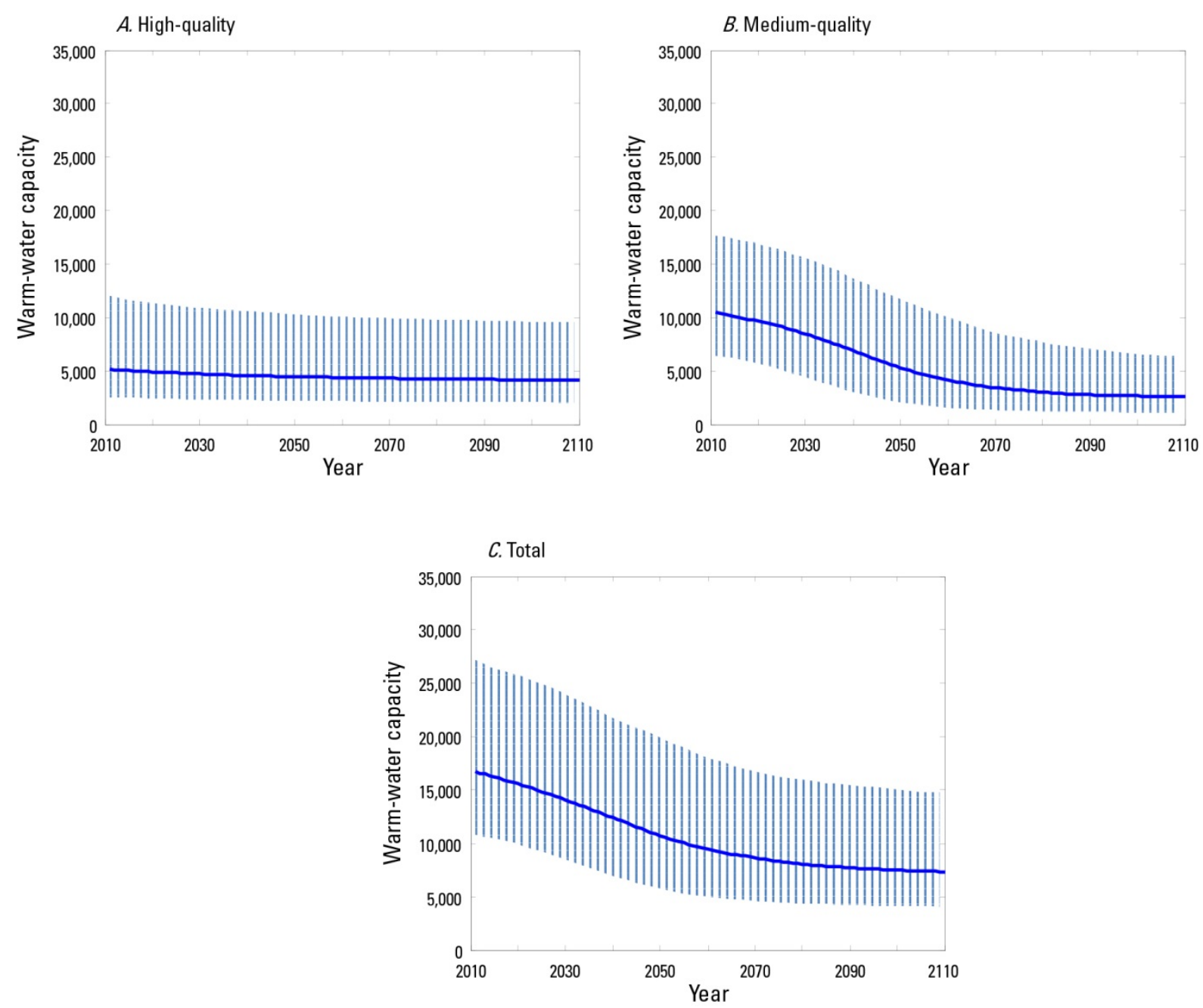

Figure 1. Median estimated manatee warm-water capacity over time, associated with $A$, high-quality, $B$, medium-quality, and $C$, total warm-water sites in Florida, 2010-2110. The projections incorporate the anticipated loss of industrial effluents and reduction in spring flow. The 80-percent credible intervals shown reflect uncertainty in the capacity. The projections and their uncertainty were estimated using an expert-panel process, informed by site-based empirical estimates.

\section{Survival Rates}

The regional adult manatee survival rates are shown in table 1 . In all cases, these values are higher than past estimates and considerably more precise. Using the deterministic model of Runge and others (2004), the confidence ellipses for survival and breeding rate can be superimposed on a contour plot of the asymptotic population growth rate ( $\lambda$ ) (fig. 2). In the Atlantic, Northwest, and Upper St. Johns regions, the growth rates have been demonstrably greater than 1 (positive growth) over the recent past (1983-2007). In the Southwest, the growth rate has been greater than 1, but if the severe red-tide frequency increases, the growth rate could stabilize or begin to decline. 
Table 1. Florida manatee adult survival rates for four regions in Florida, 1983-2007.

[In all cases, observations during the winter of 2008/2009 were included in the data analysis, but 1-2 annual estimates at the end of the time series were dropped because of concerns about bias. Note that the estimate for the Southwest region is for years in which there is not a severe red-tide. Source: Langtimm and others, U.S. Geological Survey, written commun., 2015]

\begin{tabular}{llll}
\hline \multicolumn{1}{c}{ Region } & Mean & Standard Error & Years \\
\hline Atlantic & 0.967 & 0.004 & $1983-2007$ \\
Upper St. John's & 0.975 & 0.004 & $1986-2006$ \\
Northwest & 0.977 & 0.003 & $1983-2007$ \\
Southwest & 0.971 & 0.004 & $1996-2007$ \\
\hline
\end{tabular}

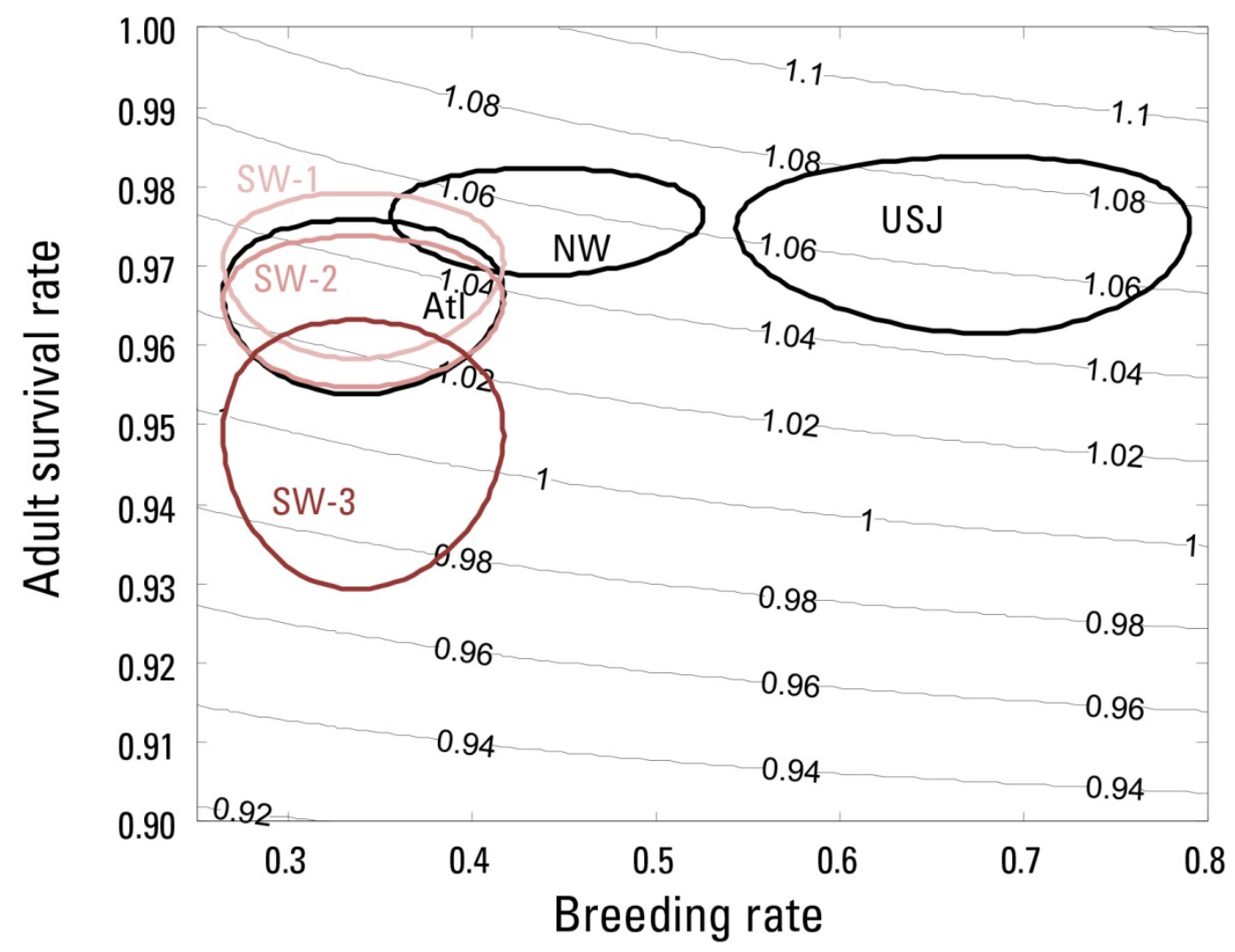

Figure 2. Contour plot of the asymptotic population growth rate $(\lambda)$ as a function of adult survival rate and breeding rate. The ellipses show the 95-percent confidence bounds for the past survival and breeding rates in the four regions over the period of analysis, 1983-2007. Three ellipses are shown for the Southwest: survival rates without severe red tide (SW-1); survival rates with red tide at the rate seen in 1996-2007 (SW-2); and survival rates with constant severe red tide (SW-3). The expert panel that was consulted projected that severe red tide will be more frequent in the future than the past, suggesting an ellipse between SW-2 and SW-3. Atl, Atlantic region; NW, Northwest region; SW, Southwest region; USJ, Upper St. Johns region. 


\section{Fractions of Mortality}

The fractions of mortality owing to watercraft, water-control structures, entanglement in marine debris, cold stress, and red tide for the period 2001-09 are shown in table 2. In some cases, the 95-percent credible intervals are quite wide, especially for the Upper St. Johns and Southwest regions because of the uncertainty induced by the carcasses for which cause of death could not be determined, but note that this uncertainty is bounded. For example, in the Atlantic region during 2001-09, watercraft was known to be the cause of death for 276 adult and subadult carcasses, water-control structures for 6 , marine debris for 7 , cold stress for 28 , red tide for 9 , and other causes for 90 . The cause of death could not be determined for an additional 210 carcasses (total 626). Thus, the fraction of mortality owing to watercraft alone must be at least 0.441 (276/626), which would be the case if none of the unknown carcasses were due to watercraft. If the causes of death for the unknown carcasses are in the same proportions as for the known carcasses, then the fraction of mortality owing to watercraft would be 0.663 (276/416). Finally, on the upper end, if all of the unknown carcasses resulted from watercraft, then the fraction of mortality would be $0.776(486 / 626)$. Thus, the fraction of adult mortality owing to watercraft in the Atlantic region is bounded by $(0.441,0.776)$. The Bayesian analysis reflects these bounds and provides some additional precision so that the 95-percent credible interval is $(0.56,0.69)$. The posterior distributions for the fractions of adult mortality owing to watercraft are shown for the Southwest and Atlantic regions (fig. 3). The proportion of deaths owing to watercraft in the Southwest region is lower than in the Atlantic region because of the inclusion of background red-tide mortality in the former. Note that had two other "non-red tide" years $(2002,2007)$ with moderate red-tide mortality been excluded from background calculations, then the proportion of adult deaths owing to watercraft in the Southwest region would have been similar to that in the Atlantic region. 
Table 2. Fractions of mortality due to various causes based on Bayesian analysis of the carcass salvage data, 2001-09.

[The mean and 95-percent credible intervals (CI) from the posterior distributions are shown; the credible intervals reflect uncertainty in the estimate of these parameters. Five of the causes are shown, while the sixth (other causes) is the complement of their sum. Water-control structure (WCS) mortality includes entrapment and crushing in gates and locks. In the Southwest, the fractions of mortality are for years in which there is not a severe red tide; in such years, the red-tide fraction increases and all other fractions decrease proportionally. In the Upper St. Johns region, red tide is not observed and is assumed to never occur, thus no credible interval is calculated (--)]

\begin{tabular}{|c|c|c|c|c|c|}
\hline \multirow{2}{*}{ Region } & \multirow{2}{*}{ Cause } & \multicolumn{2}{|c|}{ Adult } & \multicolumn{2}{|c|}{ Calf } \\
\hline & & Mean & $95 \% \mathrm{Cl}$ & Mean & $95 \% \mathrm{Cl}$ \\
\hline \multicolumn{6}{|l|}{ Atlantic } \\
\hline & Watercraft & 0.62 & $(0.56,0.69)$ & 0.16 & $(0.12,0.22)$ \\
\hline & WCS & 0.01 & $(0.00,0.02)$ & 0.00 & $(0.00,0.01)$ \\
\hline & Marine debris & 0.01 & $(0.00,0.02)$ & 0.01 & $(0.00,0.02)$ \\
\hline & Cold stress & 0.10 & $(0.06,0.15)$ & 0.49 & $(0.40,0.58)$ \\
\hline & Red tide & 0.05 & $(0.02,0.10)$ & 0.03 & $(0.01,0.11)$ \\
\hline \multicolumn{6}{|l|}{ Upper St. Johns } \\
\hline & Watercraft & 0.50 & $(0.29,0.78)$ & 0.61 & $(0.27,0.88)$ \\
\hline & WCS & 0.05 & $(0.01,0.13)$ & 0.07 & $(0.00,0.24)$ \\
\hline & Marine debris & 0.05 & $(0.01,0.13)$ & 0.06 & $(0.00,0.26)$ \\
\hline & Cold stress & 0.31 & $(0.08,0.55)$ & 0.18 & $(0.03,0.46)$ \\
\hline & Red tide & 0.00 & -- & 0.00 & -- \\
\hline \multicolumn{6}{|l|}{ Northwest } \\
\hline & Watercraft & 0.54 & $(0.38,0.69)$ & 0.36 & $(0.22,0.51)$ \\
\hline & WCS & 0.01 & $(0.00,0.04)$ & 0.02 & $(0.00,0.08)$ \\
\hline & Marine debris & 0.03 & $(0.01,0.08)$ & 0.02 & $(0.00,0.08)$ \\
\hline & Cold stress & 0.23 & $(0.10,0.41)$ & 0.27 & $(0.14,0.46)$ \\
\hline & Red tide & 0.02 & $(0.00,0.06)$ & 0.02 & $(0.00,0.08)$ \\
\hline \multicolumn{6}{|l|}{ Southwest } \\
\hline & Watercraft & 0.47 & $(0.43,0.50)$ & 0.24 & $(0.17,0.31)$ \\
\hline & WCS & 0.03 & $(0.02,0.06)$ & 0.00 & $(0.00,0.01)$ \\
\hline & Marine debris & 0.01 & $(0.00,0.02)$ & 0.00 & $(0.00,0.01)$ \\
\hline & Cold stress & 0.08 & $(0.05,0.10)$ & 0.39 & $(0.33,0.45)$ \\
\hline & Red tide & 0.32 & $(0.28,0.36)$ & 0.23 & $(0.16,0.30)$ \\
\hline
\end{tabular}




\section{A. Southwest}

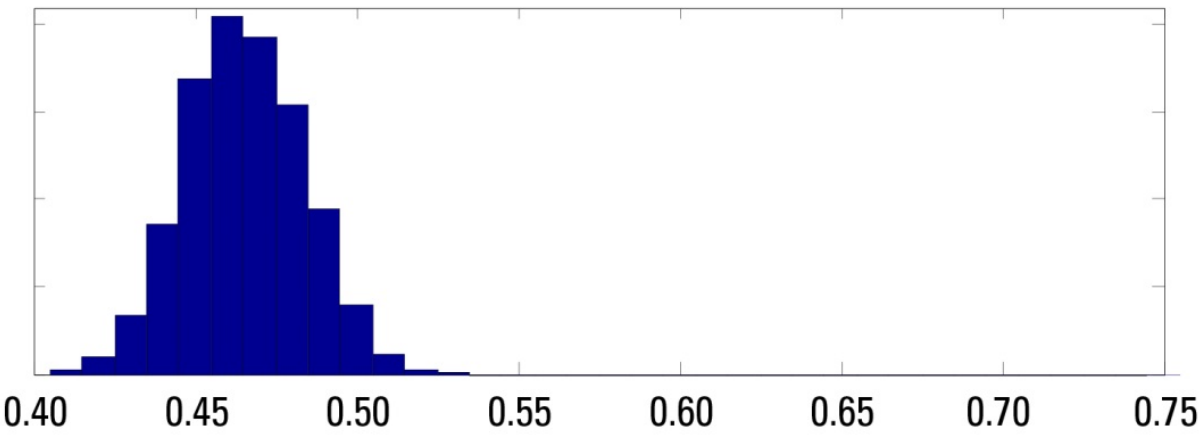

\section{B. Atlantic}

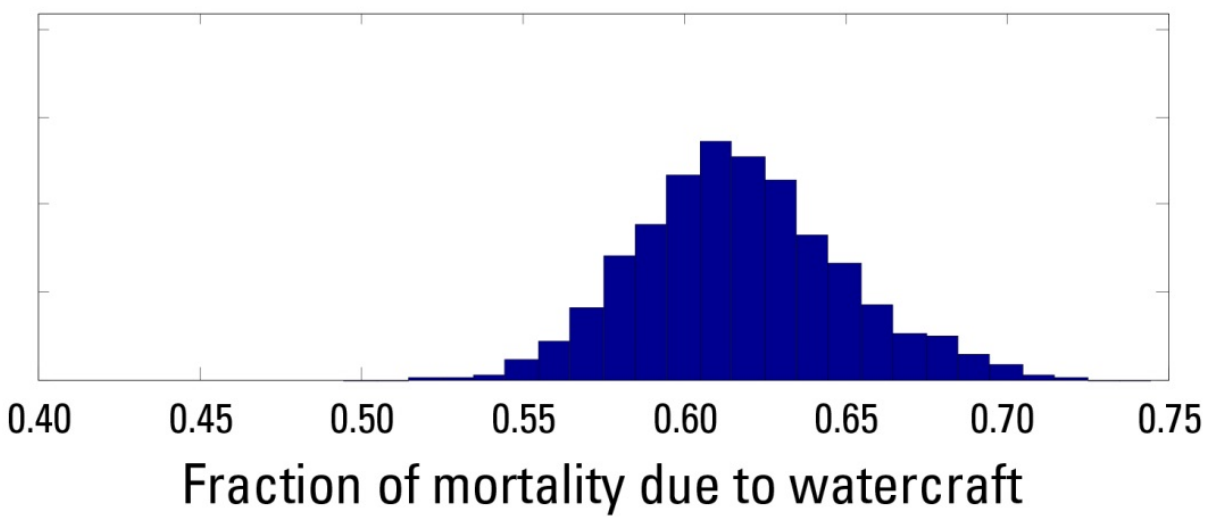

Figure 3. Histograms of fraction of adult mortality resulting from watercraft, based on data from 2001 to 2009 for the $A$, Southwest and B, Atlantic regions of Florida. These histograms are posterior distributions from the Bayesian analysis of the carcass salvage data and reflect the range of uncertainty in these parameters. These two fractions of mortality are shown for purposes of illustration; the credible intervals for all fractions of mortality are listed in Table 2.

\section{Total Population Size}

Under the status quo scenario, the statewide population is expected to increase slowly, nearly doubling over 50 years, then stabilize as the population reaches a statewide carrying capacity (fig. 4). In the average projection, little decline is seen in the long term, largely because the loss of warm-water capacity is expected to occur before the population reaches the long-term carrying capacity. The model for warm-water capacity assumes that the capacity stabilizes at some lower level in about 50 years, after all the industrial plants are closed and further decreases in spring flow are halted; the mean population size stabilizes in turn, although it takes some time for this to occur. There is considerable uncertainty in the future projections of population size, as shown by the wide projection intervals. This uncertainty arises from uncertainty about the underlying demographic parameters that drive this population, uncertainty about the current and future warm-water capacity, and chance future events (stochasticity). Nevertheless, the model predicts that it is unlikely $(<2.5$-percent chance) the statewide population will fall below 4,000 individuals over the next 100 years, assuming the current threats remain at their current levels indefinitely. 


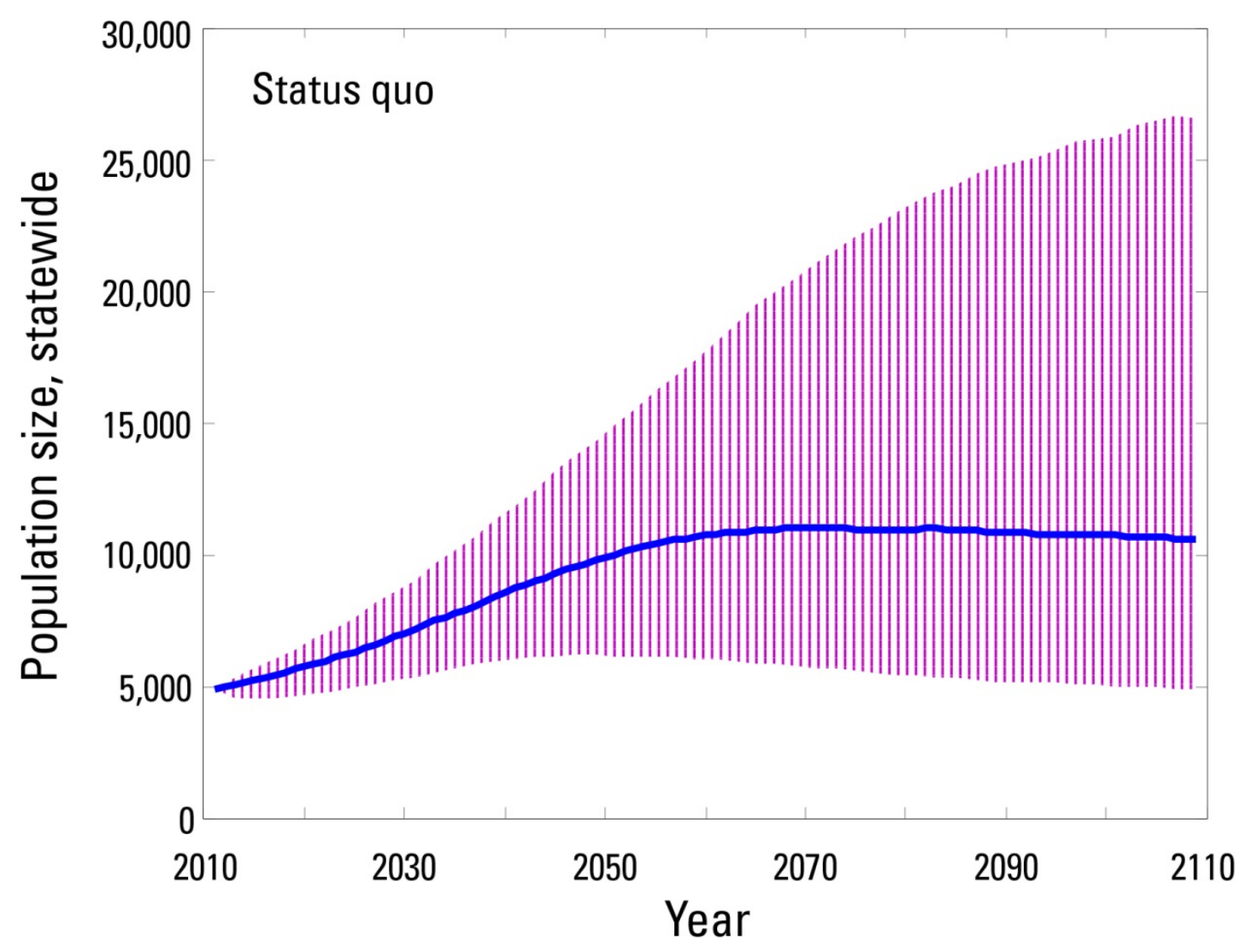

Figure 4. Projected Florida manatee population size under the status quo scenario, 2010-2110. The bold line depicts the median population size; the shaded area represents the 90-percent projection intervals.

Under the status quo scenario, a substantial shift in the distribution of manatees within the State is expected with the Northwest and Upper St. Johns regions showing large projected increases, and the Southwest and Atlantic regions showing moderate long-term decreases (fig. 5). Currently, 17.4 percent of the statewide population is found in the Northwest and Upper St. Johns regions (based on the 2011 synoptic survey); this is expected to increase to 69.6 percent in 100 years (based on the mean projections from the status quo scenario). In both the Northwest and Upper St. Johns regions, the warmwater expert panel estimated that there is substantially more capacity for manatees than is currently realized, and while this capacity is expected to decrease owing to loss of spring flow, most of that loss is expected to occur before the manatee population increases enough to reach capacity, thus no observed decline is expected in the median projections (fig. 5). In the Southwest and Atlantic regions, however, the long-term capacity is not estimated to be substantially larger than the current population sizes because substantial loss of capacity is expected through the loss of industrial effluents. Thus, the populations are expected to increase slightly over the next several decades but then show long-term decline with the loss of warm-water capacity (fig. 5). 


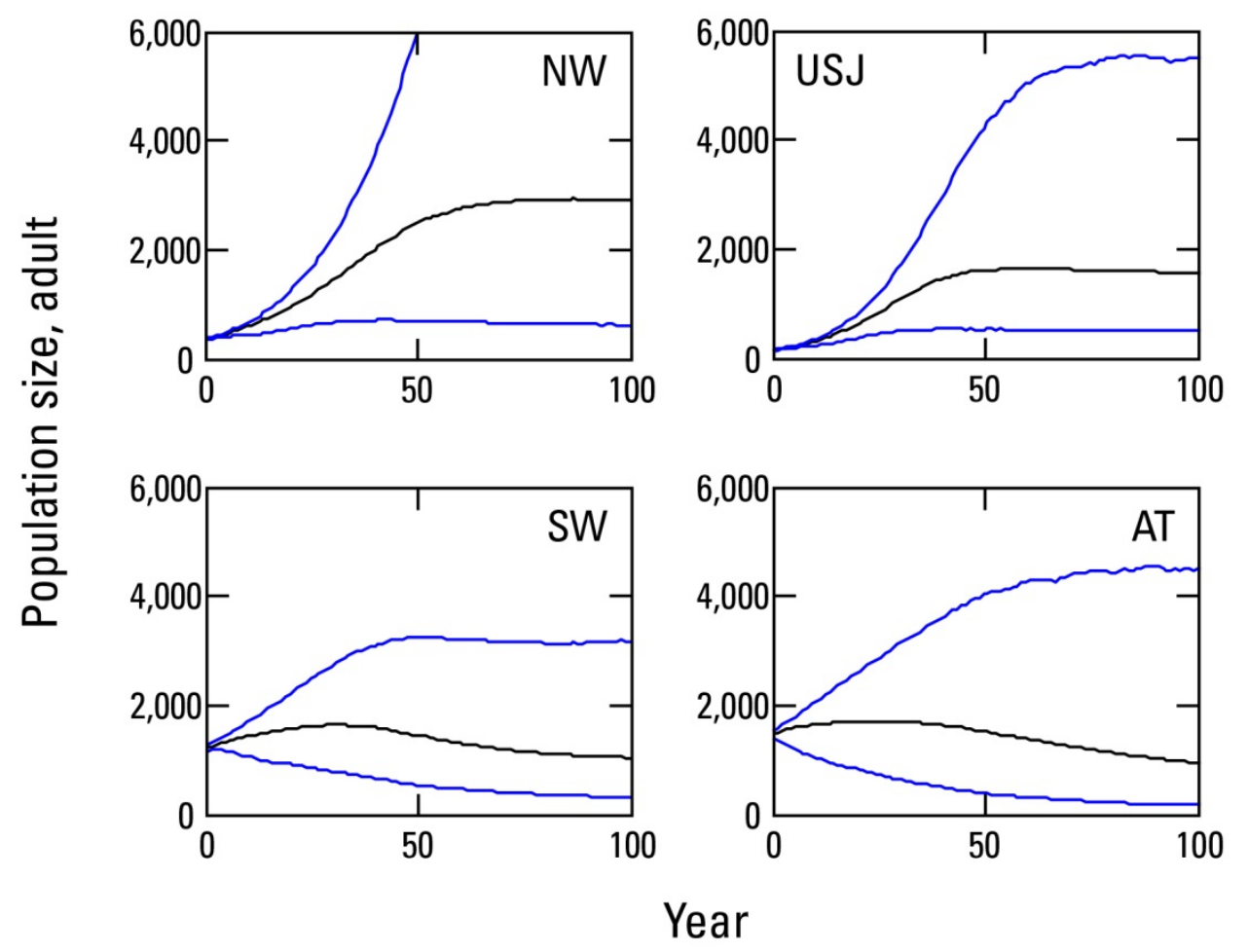

Figure 5. Projected adult population size in four regions of Florida, 2010-2110 (0 to 100 years from now), under the status quo scenario. The black line depicts the median population size; the blue lines represent the 90-percent projection intervals. Atl, Atlantic region; NW, Northwest region; SW, Southwest region; USJ, Upper St. Johns region.

\section{Regional Analysis of Quasi-Extinction}

The analysis of the statewide total population, however, does not tell the whole story; a more nuanced interpretation requires attention to the dynamics of the population on each coast of the State and to effective (adult males and females) instead of total (including non-reproductive age adults) population size. Two points are worth making here with regard to the measure of status we have assumed. First, although the model might not project that the total population size will slip below, for example, 500 animals with any sizeable probability, the probability of the effective population size falling below the same threshold is higher. If the effective population size falls too low, a loss of genetic diversity might result, with the consequence that the subspecies could lose some ability to adapt to future environmental change. So, attention to effective population size (or its surrogate here, adult population size) is warranted. (As a reminder, in this study, effective population size is equal to the adult population size, but it is probably more appropriate to associate the effective population size with approximately one-half of the adult population size.) Second, because the model assumes the populations on the two coasts are independent (an assumption that is reasonable given their geographic separation), losses on one coast are not likely to occur simultaneously with losses on the other coast. Thus, the statewide population size can mask a substantial change in distribution of manatees. Since loss of one of the coastal populations of Florida manatee could be interpreted to constitute extinction in a "significant portion of its range" (ESA, 16 U.S.C. § 1532(6)), we focused on analysis of the coastal populations. 
On the Gulf coast, there is a very low probability $(0.24 \%)$ that the effective population could fall below 500 animals within 150 years under the status quo scenario (figs. $6 A, 7 A$ ). The major threats, as we understand the dynamics now, are watercraft-related mortality, loss of warm-water habitat, and red tide; removal of any one of these threats reduces the very low risk of quasi-extinction to a negligible level. The other threats (water-control structures, entanglement with marine debris) are roughly equivalent in magnitude to each other but have substantially less effect than the major threats.
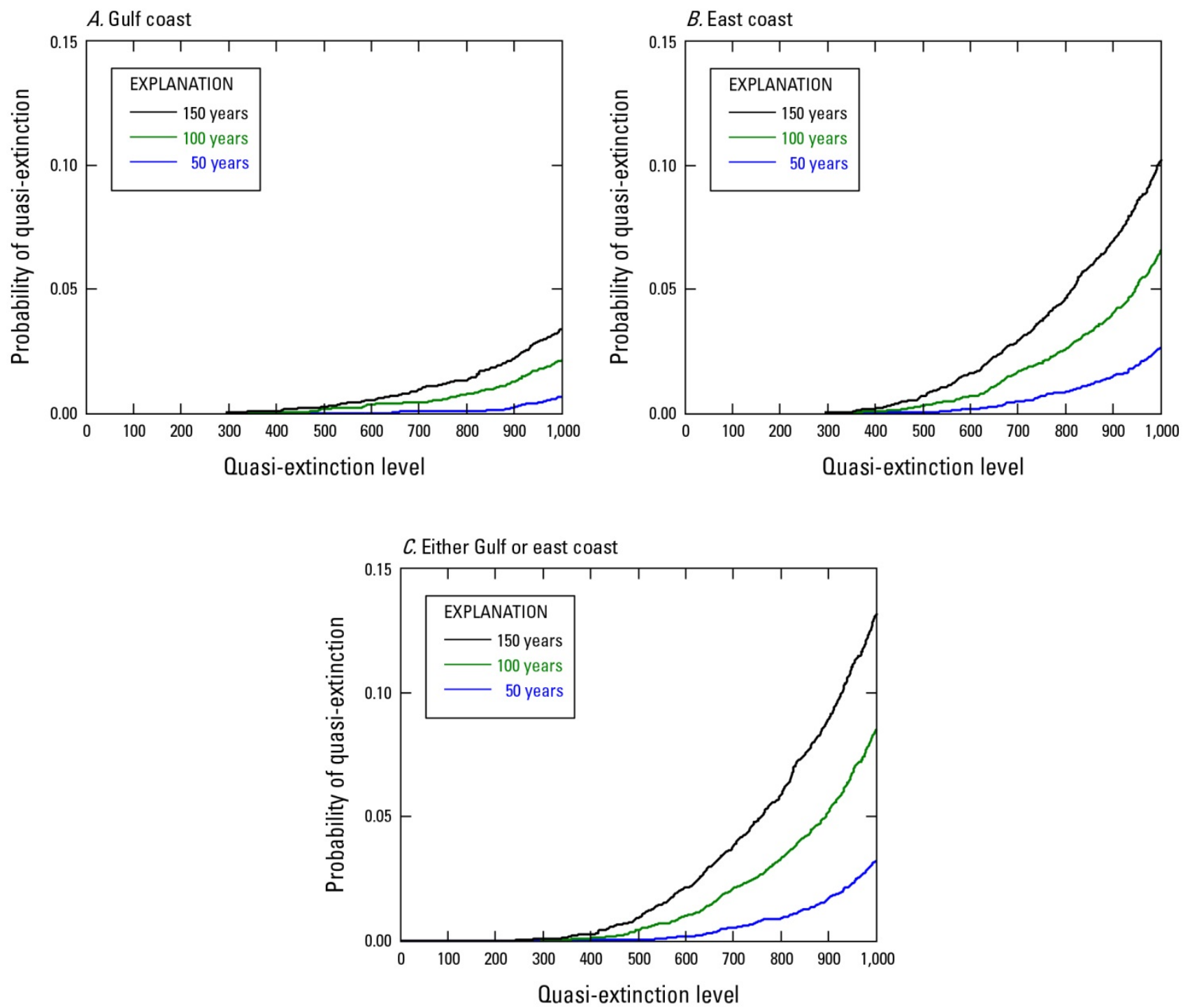

Figure 6. Probability of the adult (effective) population falling below a threshold within 50,100 , or 150 years, as a function of the threshold, for the status quo scenario, on $A$, the Gulf coast, $B$, the East coast, or $C$, either coast of Florida. 

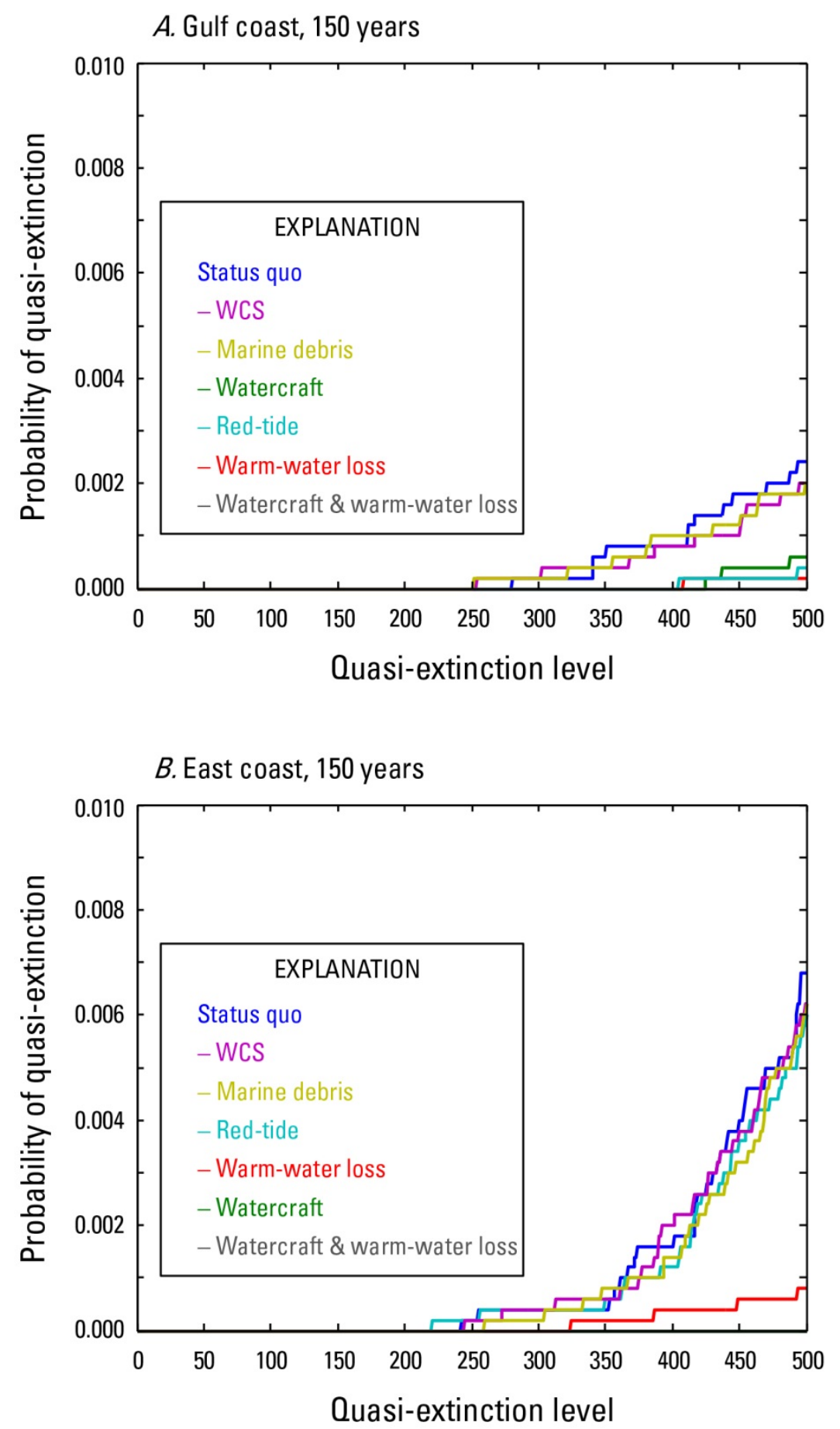

Figure 7. Probability of the adult (effective) population falling below a threshold within 150 years, as a function of the threshold, for the status quo and six threat scenarios, on $A$, the Gulf coast, or $B$, the East coast of Florida. In panel $A$, the watercraft \& warm-water loss line overlaps the horizontal axis. In panel $B$, the watercraft and the watercraft \& warm-water loss lines overlap the horizontal axis. The minus sign (-) in the Explanation indicates the corresponding threat was removed. WCS, water-control structure. 
On the East coast, the probability that the effective population would fall below 500 within 150 years under the status quo scenario is 0.68 percent, a bit higher than on the Gulf coast, but still very low (figs. $6 B, 7 B$ ). In this case, watercraft-related mortality is the major threat to this coastal population, and loss of warm water is a close second. Removal of the watercraft threat reduces the risk of quasiextinction almost entirely; long-term maintenance of warm-water habitat is almost as effective.

Although red tide may increase in occurrence on the East coast, it is not identified as a substantial threat at this time.

To combine the two coastal populations and provide an overall measure of status, we calculated quasi-extinction as the probability that either coastal population would fall below some particular threshold (figs. $6 C, 8$; table 3 ). Thus, for example, the probability that the effective population size will fall below 500 animals on either coast within 150 years under the status quo scenario is 0.92 percent (higher than the individual coastal probabilities, as expected). Using this formula as a measure of statewide status, the analysis shows that watercraft-related mortality is the single largest threat to the Florida manatee population; full removal of this threat would reduce the probability of the effective population falling below 500 on either coast in 150 years from 0.92 percent to 0.06 percent (fig. 8, table $3)$. Watercraft-related mortality is the greatest threat across all thresholds for quasi-extinction and all time frames. Water-control structures, red tide, and entanglement with marine debris are weaker threats across all time frames and thresholds. The loss of warm water is the second greatest threat at higher quasi-extinction thresholds and longer time frames, but it is not as large a threat in the short-term $(<50$ years). In other words, the effect of the loss of warm water takes longer to be felt because the initiation of the threat is delayed. 


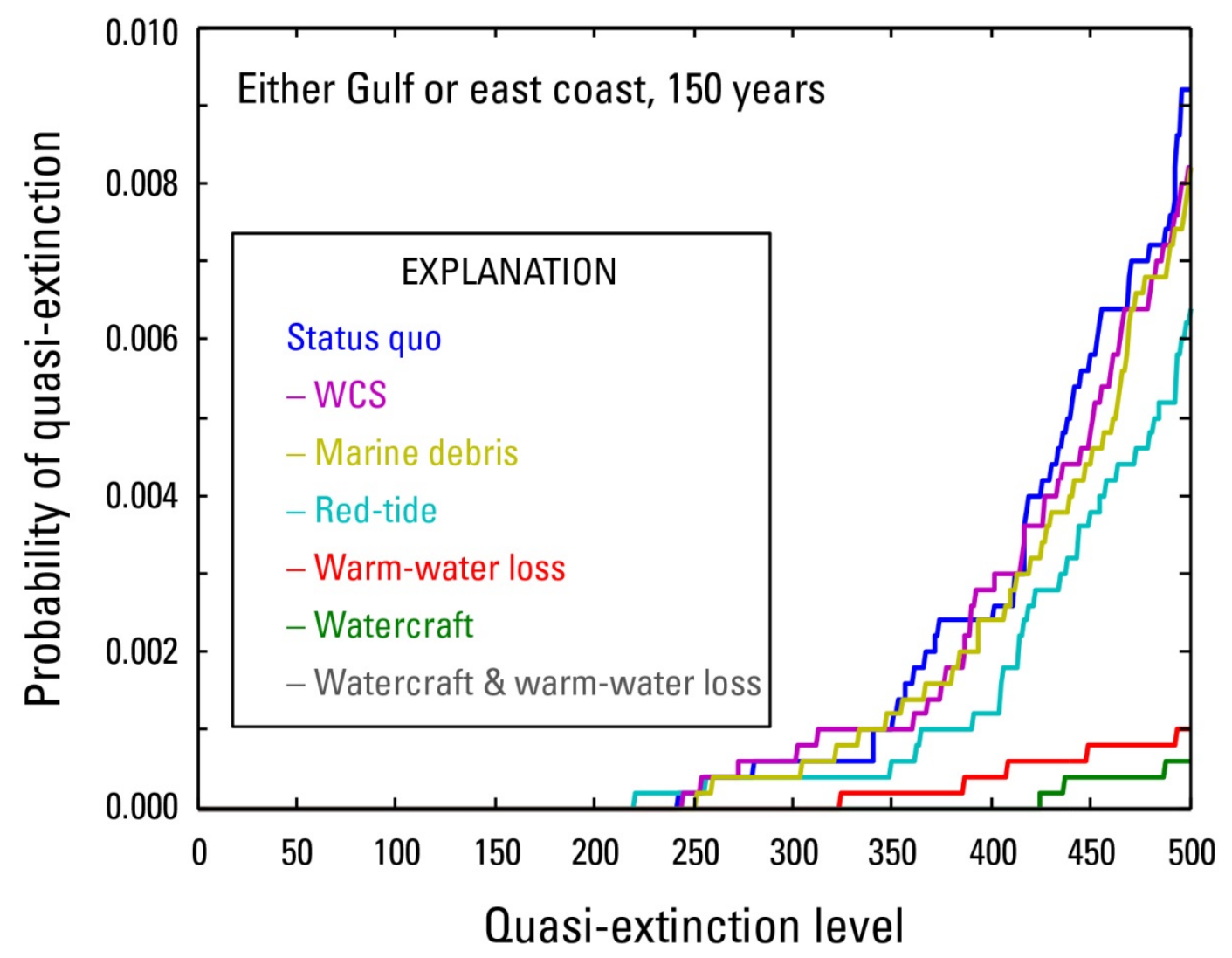

Figure 8. Probability of the adult (effective) population falling below a threshold on either the Gulf or the East coast of Florida within 150 years, as a function of the threshold, for the status quo and six threat scenarios. The status quo scenario is shown with a solid, blue line. The other scenarios consider the one-by-one removal of major threats. The line for the simultaneous removal of the watercraft and warm-water loss threats is indistinguishable from the horizontal axis over the range shown. The minus sign (-) in the Explanation indicates the corresponding threat was removed. WCS, water-control structure. 
Table 3. Probability of the adult population falling below 100,250 , or 500 animals on either the Gulf coast or the East coast of Florida in 50 to 150 years.

[The scenarios consider the removal of threats one at a time (except the last which removes the threats of watercraft and loss of warm water). For example, in the absence of the threat from severe red tide, the probability is 0.64 percent that the adult population will fall below 500 animals on either the East or Gulf coasts within 150 years, and the probability is 0.92 percent with the threat present at its current level (status quo). Because only 5,000 replicates were run, where the estimate is 0 , this should be understood as less than 0.0002 (less than 0.02 -percent probability of quasi-extinction)]

\begin{tabular}{|c|c|c|c|c|}
\hline \multirow[b]{2}{*}{ Scenario } & \multirow[b]{2}{*}{ Threshold } & \multicolumn{3}{|c|}{ Probability } \\
\hline & & 50 years & 100 years & 150 years \\
\hline Status quo & 100 & 0.0000 & 0.0000 & 0.0000 \\
\hline -Watercraft & 100 & 0.0000 & 0.0000 & 0.0000 \\
\hline -Warm-water loss & 100 & 0.0000 & 0.0000 & 0.0000 \\
\hline -Red tide & 100 & 0.0000 & 0.0000 & 0.0000 \\
\hline$-\mathrm{WCS}$ & 100 & 0.0000 & 0.0000 & 0.0000 \\
\hline -Marine debris & 100 & 0.0000 & 0.0000 & 0.0000 \\
\hline -Watercraft and warm-water loss & 100 & 0.0000 & 0.0000 & 0.0000 \\
\hline Status quo & 250 & 0.0000 & 0.0002 & 0.0002 \\
\hline -Watercraft & 250 & 0.0000 & 0.0000 & 0.0000 \\
\hline -Warm-water loss & 250 & 0.0000 & 0.0000 & 0.0000 \\
\hline -Red tide & 250 & 0.0000 & 0.0002 & 0.0002 \\
\hline$-\mathrm{WCS}$ & 250 & 0.0000 & 0.0002 & 0.0002 \\
\hline -Marine debris & 250 & 0.0000 & 0.0000 & 0.0000 \\
\hline -Watercraft and warm-water loss & 250 & 0.0000 & 0.0000 & 0.0000 \\
\hline Status quo & 500 & 0.0004 & 0.0042 & 0.0092 \\
\hline -Watercraft & 500 & 0.0000 & 0.0000 & 0.0006 \\
\hline -Warm-water loss & 500 & 0.0004 & 0.0006 & 0.0010 \\
\hline -Red tide & 500 & 0.0004 & 0.0024 & 0.0064 \\
\hline$-\mathrm{WCS}$ & 500 & 0.0004 & 0.0042 & 0.0082 \\
\hline -Marine debris & 500 & 0.0004 & 0.0040 & 0.0082 \\
\hline -Watercraft and warm-water loss & 500 & 0.0000 & 0.0000 & 0.0000 \\
\hline
\end{tabular}

One additional scenario is included in table 3 and the corresponding figures, the simultaneous removal of the threats owing to watercraft and loss of warm water. By addressing both of these threats, the estimated probability of quasi-extinction drops to less than 0.02 percent (the limit of resolution with 5,000 replicates) over 150 years for a threshold of 500 animals on either coast.

\section{Discussion}

\section{Current Status of Manatees}

The most striking result of this analysis is the substantial reduction in the estimates of quasiextinction relative to the results of the 2007 threats analysis (Runge and others, 2007b). For example, the probability of the adult population on either coast falling below 250 individuals in 100 years under the status quo scenario has decreased from 8.6 percent in the 2007 analysis to 0.02 percent in the current analysis (table 3). This is primarily a reflection of our increased understanding of the status of the population rather than an actual improvement in the status of the population, although there are some elements of the latter.

The major changes to the CBM have been updates in the estimates of survival rates and warmwater capacity. Through dedicated effort by the staff of USGS Sirenia Project, FWRI, and Mote, the MIPS database has been extended 7 years. The separate databases are now merged into a single database, and there is an increased ability to match carcasses from the necropsy program to individuals in the photo-identification database. Added to this, there are now new methods being used to integrate 
photo-identification sightings during the winter, photo-identification sightings outside the winter period, and carcass recoveries into a single analysis. The scientific basis of the Barker/RD mark-recapture survival estimation model has been thoroughly vetted in peer reviewed publications in scientific journals (Kendall and others, 2013; Peñaloza and others, 2014). The case studies demonstrating the efficacy of this new approach are based on the Florida manatee and photo-identification monitoring data. The result is that the survival rates are now more accurate and more precise than previous rates. This is particularly true in the Southwest region where estimates of adult mean survival rate have increased from 0.908 in the 2007 analysis to 0.971 in the current analysis (in years without a red-tide event). As explained by Runge and others (2007a,b), the projections from the CBM are particularly sensitive to changes in adult survival rate; increases in adult survival rate confer considerable resilience to the manatee population. The higher adult mean survival rate and the corresponding decrease in risk of quasi-extinction, however, are primarily a result of increases in our understanding of these rates; there is no evidence of a positive trend in survival rates between the last analysis and this one.

The new estimates of warm-water capacity also contributed to the changes in our understanding of the status of the Florida manatee population. In the 2007 analysis, the estimates of warm-water capacity were based on an expert panel process that occurred during 2002-03. The expert panel that met during 2011-12 had access to nearly a decade of additional experience observing manatees in warmwater aggregations, as well as site-specific empirical data (Provancha and others, 2012). Further, the process that was used to elicit estimates from the experts was more rigorous and paid greater attention to uncertainty. The estimates of warm-water capacity are now more than twice as high in all regions (fig. 1) than they were in the previous analysis. Again, this should not be attributed to actual improvements in winter manatee habitat, but rather a better understanding of how manatees use existing habitat and how much of it there might be; in some areas, observed population sizes have exceeded the earlier estimates of warm-water capacity. As noted in the 2007 analysis (Runge and others, 2007b), higher warm-water capacity conveys a buffering effect to the population dynamics, reducing the risk of quasiextinction simply by allowing the population to fluctuate around a higher mean.

We also updated the initial population size and the fractions of mortality, and in these cases, the change in assessment may indeed reflect an actual change in status. During the 2011 synoptic survey 4,834 manatees were counted (compared to 3,329 in the 2001 synoptic survey). Although there are serious methodological issues (detection probability) that may contribute to this increase in statewide count, it is likely that some of that increase reflects an actual increase in the population size. Such growth of the population is consistent with other indicators of status (for example, the estimated population growth rates; fig. 2). In the CBM, a higher initial population size will result in lower estimates of quasi-extinction risk, all other things being equal.

We used a more recent period for the analysis of the fractions of mortality (2001-09 rather than 1986-2004), and it is evident that the causes of mortality have changed to some degree. Most notably, death in water-control structures, which was once a substantial contributor to manatee mortality, is normally a rare event (save in 2012, when the manatee protection system at a single lock structure failed, resulting in six deaths).

Some may view these results and conclude that we were overly cautious in our previous analysis because new information now indicates that the manatee population has a low probability of quasiextinction (table 3). We maintain that our results have always been a fair depiction of the current state of knowledge and have appropriately incorporated and articulated the uncertainty about that state of knowledge. The risk of quasi-extinction incorporates two kinds of uncertainty: so-called aleatory uncertainty (the random fluctuations that affect populations) and epistemic uncertainty (our incomplete knowledge of aspects of the population dynamics). Both of these uncertainties contribute to concerns 
about the long-term risk of a population. In this case, reduction of epistemic uncertainty has led to lower estimates of quasi-extinction; it could have been otherwise.

\section{Threats Analysis}

The ranking of the threats remains largely the same as it was in the 2007 analysis. Statewide, watercraft-related mortality makes the largest contribution to the risk of quasi-extinction; full removal of this one threat would reduce the risk of quasi-extinction to near negligible levels (fig. 8, table 3 ). The threat from the loss of warm water again ranks second, with a risk about as great as the risk from watercraft. The ranking of threats on the East coast is similar to the comparable ranking in 2007 (fig. $7 B$ ). The major changes to the threats assessment are found on the Gulf coast (fig. $7 A$ ), where the effects of red tide and loss of warm water are stronger than the effect of watercraft-related mortality. In part this is the result of the increased estimate of adult survival in the Southwest (hence, a lower estimate for watercraft-related mortality) and the anticipated continued increase in the frequency of severe red-tide mortality.

An understanding of the threats analysis needs to be informed by the overall interpretation of the status of the population. Although the ranking of the threats remains roughly the same, the absolute strength of those threats is now understood to be less because we now understand the population to be more resilient than we had previously thought.

\section{Caveats}

In the comparison of threats, it is important to keep in mind that for the status quo scenario, it was assumed that the various threats operate at their current levels indefinitely (except for warm-water loss, which doesn't happen for some years). In some cases, a better statement about status quo might include continued trends for some threats. For instance, there is debate about whether or not watercraftrelated mortality is currently stable and how we should forecast this threat (Calleson, 2014). Since 2008, with the economic downturn, boater registrations have decreased statewide, so one might argue watercraft-related mortality might have decreased. But, what will happen as economic growth returns and boating activity increases again? Likewise, trends in other threats are possible, and new threats could arise. For example, the Indian River Lagoon - an area encompassing major foraging habitat for manatees in the Atlantic region-experienced unprecedented losses of seagrass habitat in 2011 and 2012 from extensive algal blooms (St. Johns River Water Management District, written commun., 2012). This analysis does not incorporate all the possible changes that could occur in the future, but it does integrate our understanding of current and foreseeable threats in a common risk analysis framework.

One of the most important questions that has not yet been incorporated into the CBM concerns the implications of the severe cold in the winters of 2009-10 and 2010-11. A significant shift in the fractions of mortality occurred during those winters, with a considerable fraction of mortality from cold stress. If these just happened to be two severely cold winters that are otherwise compatible with the annual variation captured in the CBM, then these winters might not change our understanding of manatee status. However, if these winters are harbingers of a changing winter climate and such winters are expected to occur more frequently in the future, then this might very well raise the estimates of quasi-extinction risk. There are two scientific challenges that face us in understanding the effects of cold. First, as of 2012, we did not yet have estimates of the effects of these winters on regional survival rates. In the 2015 update, enough photo-identification data may be available to begin to estimate the effect of those years on survival rates. Second, there is an important question about the mechanism by which cold of this magnitude is affecting the population dynamics. Was the effect of these cold events 
density independent; that is, did it affect all individuals across the exposed population, or was it densitydependent? In the latter case, the mortality may have resulted from exposure of animals that had been forced out of the best warm-water habitat because of limited capacity. These two mechanisms will have quite different effects on the long-term risk faced by the population. In the former case, an increase in density-independent mortality will result in a strong increase in the risk of quasi-extinction. In the latter case, the increased mortality is largely an indication that the population is near capacity (or at least near capacity around the sites with high historical fidelity), and the risk of quasi-extinction will not be strongly affected. These questions are an area of active research.

These results integrate the best scientific information that was available as of December 2012, but several other caveats about these results reflect data gaps. (1) Calf and subadult survival rates are based on estimates from a relatively small group of animals that overwinter in the Upper St. Johns region; rates were extrapolated to other regions. The ratios of calf to adult mortality and subadult to adult mortality in other regions could differ from those in the Upper St. Johns region. This is not, however, likely to affect the results a great deal because the demographic results are relatively insensitive to these survival rates. (2) The reproductive rate for the Southwest region was assumed to be the same as the Atlantic region rate. An empirical estimate of reproductive rate for the whole Southwest region has not been available in the past, but new data and analyses are emerging for use in future updates to the CBM. (3) The predicted long-term frequency of red tide was based on expert judgment from a small panel of experts. The model implements this frequency immediately. A trend from the current rates to the long-term rates might better represent the dynamics of this threat. (4) There is still considerable uncertainty about warm-water capacity, including its magnitude and the mechanism by which it affects manatee population dynamics. We have captured that uncertainty as best we can in this modeling work, but continued attention over time is warranted. (5) The CBM is not designed to capture short-term dynamics, but rather to look at long-term manatee population dynamics. Thus, for example, the long-term effect of the closing of a power plant is incorporated into the results (via loss of carrying capacity), but we have not attempted to forecast the short-term effects of such a shutdown (such as the mortality of animals with high fidelity to that location). (6) The CBM does not yet incorporate the potential effects of climate change on manatee habitat or demography.

\section{Next Steps}

As noted earlier, work is ongoing in 2015 to update the CBM with the most recent data and to explore several important questions. These updates will include the following:

- Structural changes to the population model to investigate the potential effects of severe cold under several different hypotheses about its frequency in the future. This will help evaluate the possible effects of the 2009-10 and 2010-11 severely cold winters.

- Updated estimates for the cold-related mortality rates as a function of winter severity, age class, and warm-water habitat quality.

- Sensitivity analysis of the results to the behavioral rules used to distribute manatees into warmwater sites of different habitat quality.

- An updated estimate for the initial population size with the inclusion of uncertainty. Martin and others (2015) published the first statewide estimates for population size that are based on a survey design that included estimation of the probability of detection. This estimate $(6,350 ; 95 \%$ confidence interval:5,310-7,390) is higher than all previous estimates and includes an estimate of uncertainty (the synoptic surveys have no estimate of uncertainty).

- Updated estimates of adult survival and reproductive rates, including reproductive rates estimated from photo-identification data in the Southwest region. 
- Other updates to parameter estimates through empirical analysis or expert judgment, as appropriate.

The CBM provides a framework for integrating the best available scientific information about Florida manatees. New information motivates changes to the structure of the CBM and provides new updates for the parameters; the CBM evolves to accommodate this new information. The work provided in this report summarizes changes in the best available information from 2007 through 2012; ongoing work will update the CBM to reflect new information through 2015.

\section{Acknowledgments}

The work described in this report would not be possible without the extraordinary efforts of the field biologists, data managers, and analysts who have studied Florida manatees over the last three decades. We are particularly grateful to Cathy Beck, Amy Teague, Gaia Meigs-Friend, Howard Kochman, Claudia Peñaloza, Kari Rood, Sheri Barton, Chip Deutsch, and Holly Edwards. This work has also benefitted from conversations with marine mammal experts who have generously shared their insights, among them, Nicole Adimey, Brandon Bassett, Bob Bonde, Dave Bruzek, Alina Corcoran, Chip Deutsch, Martine deWit, Leanne Flewelling, Jodie Gless, Bill Kendall, Jan Landsberg, Gary Mahon, Ron Mezich, Lori Morris, Sheila O’Dea, Buddy Powell, Jane Provancha, Jim Reid, John Reynolds, Monica Ross, Dan Slone, Kent Smith, Karen Steidinger, Jacob Tustison, Jim Valade, and Leslie Ward-Geiger. Dawn Jennings and Jim Valade have been instrumental in explaining the statutory and regulatory context for threats analysis under the ESA. Carol Sanders-Reed provided critical support to develop and maintain the MATLAB code for the CBM. We are grateful to Chip Deutsch, Bill Kendall, Jessica Stanton, and Ruth Larkins, who carefully reviewed this report and offered suggestions that have improved it substantially.

\section{References Cited}

Barlas, M.E., Deutsch, C.J., de Wit, M., and Ward-Geiger, L.I., 2011, Florida manatee cold-related unusual mortality event, January-April 2010: St. Petersburg, Florida, USA, Florida Fish and Wildlife Conservation Commission, $138 \mathrm{p}$.

Burnham, K.P., Anderson, D.R., White, G.C., Brownie, C., and Pollock, K.H., 1987, Design and analysis methods for fish survival experiments based on release-recapture: American Fisheries Society Monograph, v. 5, p. 1-437.

Calleson, C.S., 2014, Issues and opportunities associated with using manatee mortality data to evaluate the effectiveness of manatee protection efforts in Florida: Endangered Species Research, v. 26, p. $127-136$.

Kendall, W.L., Barker, R.J., White, G.C., Lindberg, M.S., Langtimm, C.A., and Peñaloza, C.L., 2013, Combining dead recovery, auxiliary observations and robust design data to estimate demographic parameters from marked individuals: Methods in Ecology and Evolution, v. 4, no. 9, p. 828-835.

Langtimm, C.A., 2009, Non-random temporary emigration and the robust design: Conditions for bias at the end of a time series, in Thomson, D.L., Cooch, E.G., and Conroy, M.J., eds., Modeling demographic processes in marked populations: Boston, Massachusetts, USA, Springer, p. 745-761.

Langtimm, C.A., Beck, C.A., Edwards, H.H., Fick-Child, K.J., Ackerman, B.B., Barton, S.L., and Hartley, W.C., 2004, Survival estimates for Florida manatees from the photo-identification of individuals: Marine Mammal Science, v. 20, no. 3, p. 438-463. 
Langtimm, C.A., O'Shea, T.J., Pradel, R., and Beck, C.A., 1998, Estimates of annual survival probabilities for adult Florida manatees (Trichechus manatus latirostris): Ecology, v. 79, no. 3, p. 981-997.

Martin, J., Edwards, H.H., Fonnesbeck, C.J., Koslovsky, S.M., Harmak, C.W., and Dane, T.M., 2015, Combining information for monitoring at large spatial scales: First statewide abundance estimate of the Florida manatee: Biological Conservation, v. 186, p. 44-51.

Peñaloza, C.L., Kendall, W.L., and Langtimm, C.A., 2014, Reducing bias in survival under nonrandom temporary emigration: Ecological Applications, v. 24, no. 5, p. 1155-1166.

Provancha, J., Taylor, C., Gimond, M., Wild, M., and Rouhani, S., 2012, K-assessment of manatee forage and warm water associated with eleven Florida sites: Merritt Island, Florida, USA, Innovative Health Applications, LLC, 123 p.

Rouhani, S., Sucsy, P., Hall, G., Osburn, W., and Wild, M., 2007, Analysis of Blue Spring discharge data to determine a minimum flow regime: St. Johns River Water Management District Special Publication, v. SJ2007-SP17.

Runge, M.C., Langtimm, C.A., and Kendall, W.L., 2004, A stage-based model of manatee population dynamics: Marine Mammal Science, v. 20, no. 3, p. 361-385.

Runge, M.C., Sanders-Reed, C.A., and Fonnesbeck, C.J., 2007a, A core stochastic population projection model for Florida manatees (Trichechus manatus latirostris): U.S. Geological Survey Open-File Report 2007-1082, 41 p.

Runge, M.C., Sanders-Reed, C.A., Langtimm, C.A., and Fonnesbeck, C.J., 2007b, A quantitative threats analysis for the Florida manatee (Trichechus manatus latirostris): U.S. Geological Survey Open-File Report 2007-1086, 34 p.

Tucker, K.P., Hunter, M.E., Bonde, R.K., Austin, J.D., Clark, A.M., Beck, C.A., McGuire, P.M., and Oli, M.K., 2012, Low genetic diversity and minimal population substructure in the endangered Florida manatee: implications for conservation: Journal of Mammalogy, v. 93, no. 6, p. 1504-1511.

U.S. Fish and Wildlife Service (FWS), 2007, West Indian Manatee (Trichechus manatus) 5-year review: Summary and evaluation: Jacksonville, Fla., FWS Jacksonville Ecological Services Office, 79 p.

White, G.C., and Burnham, K.P., 1999, Program MARK: survival estimation from populations of marked animals: Bird study, v. 46, no. S1, p. S120-S139. 
ISSN 2331-1258 (online)

http://dx.doi.org/10.3133/ofr20151083 
Back cover photograph: Florida manatee inspecting the photographer, Blue Spring State Park, 3 February 2011. Photo credit, James P. Reid, U.S. Geological Survey. 

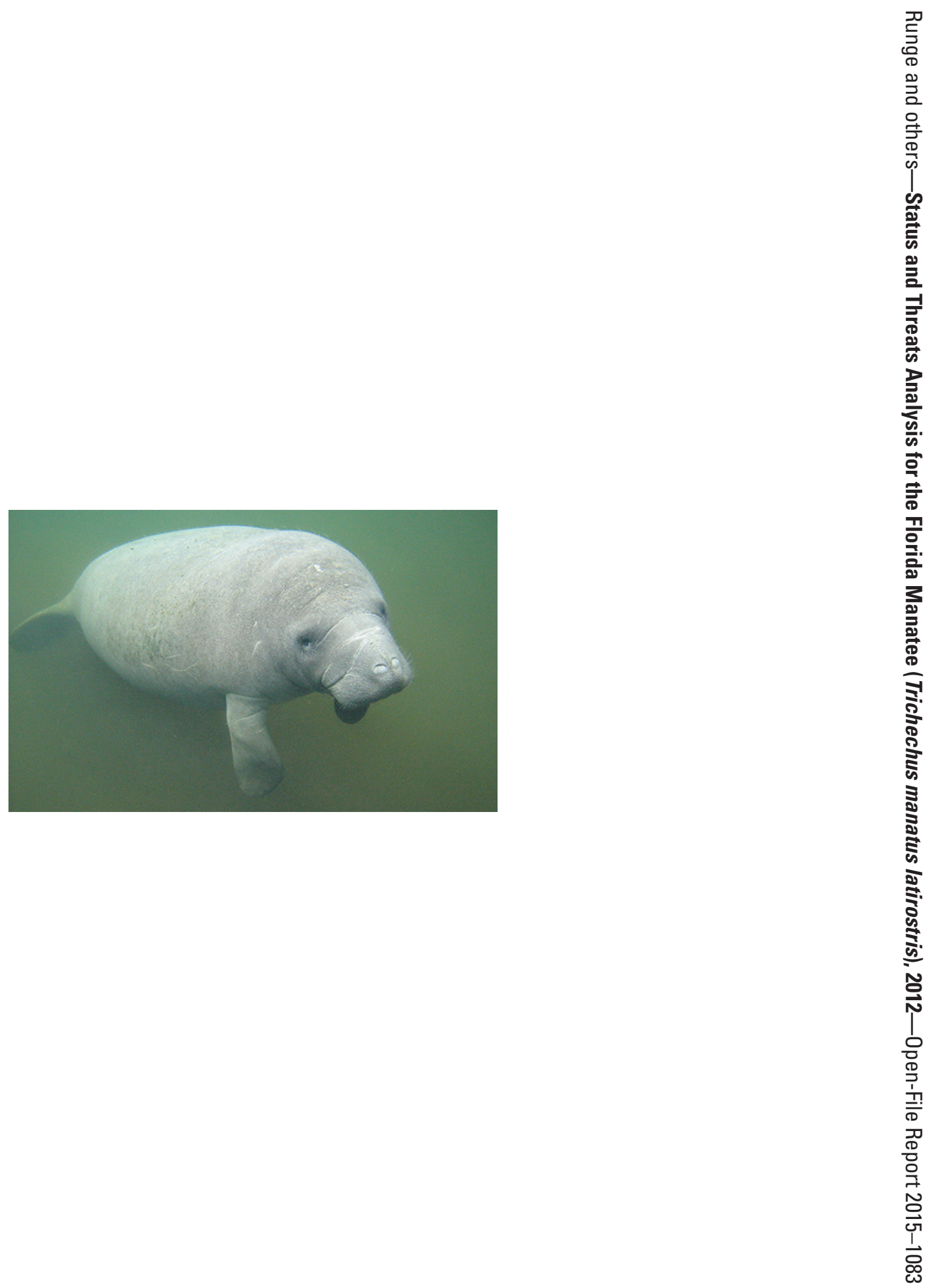